\title{
¡OH PULPO DE MIRADA DE SEDA! SEXUALIDAD Y EROTISMO EN LOS CANTOS DE MALDOROR DE LAUTRÉAMONT
}

\author{
Verónica González. Arredondo \\ Doctorado en artes de la Universidad de Guanajuato, México \\ angel_delunavioleta@hotmail.com
}

Recibido: 22 - mayo - 2016 / Aprobado: 20 - julio - 2016

\section{Resumen}

La sexualidad en Los cantos de Maldoror, de Isidore Lucien Ducasse, Lautréamont, ha tenido interpretaciones extraliterarias, desde el psicoanálisis el estudio de Marcelo Pichon-Rivière, desde la fenomenología y la poética de la ensoñación de Gaston Bachelard. Bachelard expone un bestiario en donde las formas: garra y ventosa, son símbolos de rasgadura y succión, esta última de goce sexual prolongado. En medio de la oscuridad viscosa en la que se desarrollan Los cantos, deslumbran pasajes de erotismo exacerbado: el encuentro con una hembra tiburón, el hermafrodita inmaculado y el amor por Dazet, el colega de estudios de Ducasse, el "pulpo de mirada de seda". La imposibilidad de Maldoror para identificarse en el otro como humano o ante sí, anfibio frente al espejo, origina las metamorfosis: Dazet en pulpo, hombre y mujer en hermafrodita, y mujer en tiburón. Una homosexualidad implícita, velada, la única forma en la que Maldoror puede amar.

Palabras clave: Lautréamont, Los cantos de Maldoror, poética y sexualidad.

\begin{abstract}
Sexuality at Les Chants de Maldoror (1869) by Isidore Ducasse, Lautréamont, has been interpretated extraliteraly, since psychoanalysis the study by Marcelo Pichon-Rivière, since phenomenology and the poetics of reverie by Gaston Bachelard. Bachelard exposed a bestiary where the forms: claw and ventouse are symbols of rips and sunction, the last one of extended sexual pleasure. In the middle of a viscouse darkness where Les Chants are developped, dazzles an exacerbated eroticism: the sexual encounter with a female shark, the immaculated hermaphrodite and the love for Dazet, the colleague of Studies of Ducasse, the "octopus of the silky glance!". Maldoror is unable to recognize himself in the other or in front of a mirror, leading to the metamorphosis: Dazet into an octopus, male and female into an hermaphrodite, and a women into a shark. An implicit homosexuality, hidden is the only way in which Maldoror could love.
\end{abstract}

Keywords: Lautréamont, The songs of Maldoror, poetry and sexuality. 
Que cada uno permanezica en su propia naturaleza.

Uno de los pasajes más conmovedores de Los cantos de Maldoror (1869), escritos por Isidore Lucien Ducasse, Conde de Lautréamont, es el sueño del hermafrodita que habita en medio del bosque. Son contadas las estrofas de los seis apartados que conforman Los cantos, en los que hay una quietud o un silencio sin que ocurra el asesinato o el acecho de Maldoror, y éste no es la excepción, salvo por la compasión con la que Lautréamont describe la existencia y la fragilidad de esta criatura. La atmósfera de ensueño en la que se desarrolla la estrofa, bajo el claro de luna, es casi sublime, conmovedora. El pasaje es luminoso, la naturaleza funge de mediación o protección a la debilidad del ser que habita refugiado en la noche, alejado de la sociedad por su condición corporal y sexual. El hermafrodita es bello, no ha sido aún mancillado. Lautréamont ordenará a Maldoror tener compasión de él, que representaría una proyección de sí, quizá tanto en las páginas del libro como fuera de este.

Pocos son los estudios literarios que abordan el tema de la sexualidad en Los cantos, si se considera que este no es el centro de las transformaciones de Maldoror, guiadas por el instinto animal ante la amenaza, en defensiva o en ofensiva, para inducir al lector a encontrar en él una representación del lobo-hombre que puede llegar a ser. Maldoror anda por el mundo cometiendo el asesinato a destajo, un flanêur terrible, más allá de los límites entre el animal y el hombre, la crueldad forma parte de su instinto de supervivencia, un grito expandido a lo largo de la obra, que toma su fuerza desde la naturaleza enfurecida, del mar, de los instrumentos "garra o ventosa" que utiliza en sus metamorfosis para atacar al hombre y al Creador como imagen de este. Lejos de una disertación moral, sin perder de vista la ética que conlleva el deslindar el vínculo entre animal y hombre, la estética de Los cantos reside en su búsqueda de la belleza al "cantar el mal", en la violencia descarnada que ejecuta con maestría, el amor en las entrañas de la obra, que permea, por momentos una quietud inusitada, y rasgos de la condición humana de Lautréamont / Maldoror, antes de atacar de nuevo.

Bachelard (1939) afirma en Lautréamont, "lo que la biografía no dice, la obra lo canta", aun cuando la biografía esté fuera del análisis literario de la obra, cabe destacar la obsesión del autor por "no dejar memorias" (Lautréamont, 1870). Apenas unos cuantos rastros se conocen de él, lo que cuenta ante el lector es la obra, y en relación a la sexualidad de Ducasse, es importante revisar los estudios de Enrique Pichon-Rivière, desde el psicoanálisis, y el de Bachelard, desde el complejo inconsciente en una poesía primitiva, para determinar cómo la sexualidad ejercida en un contexto histórico-social determinado, aporta otros lazos para comprender la obra, así como desde dónde surge su escritura.

\section{¡Adiós, hermafrodita!}

Allí, en un bosquecillo rodeado de flores, duerme el hermafrodita, sumido en un profundo sopor, sobre la hierba empapada en llanto. La luna ha desprendido su disco 
de la masa de nubes y acaricia, con sus pálidos rayos, ese dulce semblante de adolescente. Sus rasgos expresan la más viril energía junto a la gracia de una virgen celestial (Lautréamont, 1869, p. 140-141).

En medio del bosque, el hermafrodita duerme, exiliado por su condición al poseer ambos sexos. Rechazado por su anatomía, sueña con un mundo de seres semejantes a él, sueña que abraza a un amor que desaparece al despertar. En su cuerpo habitan un hombre y una mujer, es un ser inacabado, un engendro. Llora "una lágrima de reproche contra la Providencia”.

Cuando ve a un hombre y a una mujer paseando por una avenida flanqueada de plátanos, siente que su cuerpo se divide en dos, de abajo a arriba, y cada nuevo fragmento va a abrazar a uno de los paseantes; pero es sólo una alucinación y la razón no tarda en recuperar su poder (Lautréamont, 1869, p. 142).

Su naturaleza se manifiesta en una silueta delicada en la que confluyen el Yin: lo femenino, calmo, nocturno, receptivo; y el Yang: lo activo, diurno, masculino, principios de equilibrio en la dualidad de los contrarios, fuerzas que conforman el mundo. La criatura divina ejerce una conexión con la tierra, flora y fauna la protegen; por un lado la energía viril; por otro, la gracia virginal, ante otro ser humano es imperfecto, mas su constitución es completa. No es un ser de oscuridad, ajeno a criaturas que habitan fangosos pasajes de Los cantos, tiende al bien, contradiciendo la afirmación de Bachelard (1939): "ningún vegetalismo, símbolo de vida tranquila y confiada, es sensible en la obra de Lautréamont" (p. 12). "Sueña que es feliz; que su naturaleza corporal ha cambiado o que, al menos, ha emprendido el vuelo en una nube púrpura, hacia otra esfera, habitada por seres de su misma naturaleza" (Lautréamont, 1869, p. 143).

Aunque "le [tomen] por loco", es capaz de provocar la compasión humana. Un día, cuatro hombres enmascarados recibieron órdenes de golpearlo e internarlo en un "hospicio de alienados", comenzaron a latiguear su espalda y él / ella se defendió con sensibilidad, sabiduría y humanidad, de tal manera que otorgó el perdón a quienes le intentaron lastimar.

Les habló con tanto sentimiento, con tanta inteligencia sobre muchas ciencias humanas que había estudiado y que mostraban la gran instrucción de aquel que no había, todavía cruzado el umbral de la juventud, y sobre el destino de la humanidad, desvelando así por completo la poética nobleza de su alma, que sus guardianes, sin una gota de sangre en las venas por la acción que habían cometido, desataron sus rotos miembros, se arrastraron a sus pies solicitando un perdón que les fue concedido y se alejaron dando muestras de una veneración que, por lo común, no se concede a los hombres (Lautréamont, 1869, pp. 141-142).

Revalorado por su conocimiento, se convirtió en un ser respetado por la sociedad, sagrado. Confinado al aislamiento por considerarse un monstruo, y por temor 
al reclamo de su cuerpo ante una pareja hombre o mujer, decide por el narcisismo. El mito de Narciso y el hermafrodita son desde el psicoanálisis, el amor del sujeto a su propia imagen encontrada en el otro, de su mismo sexo. El aislamiento del hermafrodita es el de Lautréamont, alejado de la sociedad, representado desde el inconsciente en Maldoror. Tanto el hermafrodita como Lautréamont demuestran tener la genialidad del poeta y no la insania, para escapar del encierro (Pichon-Rivière, 1946). ${ }^{1}$

Desde la interpretación del inconsciente colectivo que propone Carl Jung, equivalentes en la psique a los instintos del cuerpo, los arquetipos que conforman el Tarot son entendidos como una proyección: el hermafrodita (o ser con características andróginas) se encuentra, por ejemplo, en las cartas: El Diablo y El Mundo. ${ }^{2} \mathrm{El}$ hermafrodita, próximo a Dios, sin maldad ni crueldad en él, añora ser amado; Lautréamont aleja a Maldoror del melancólico, de tocar su cabellera sagrada. "Que tu pecho se ensanche, persiguiendo la quimérica esperanza de la felicidad; te lo concedo" (Lautréamont, 1869, p. 144). Maldoror / Lautréamont ruega al cielo por él, por sí.

¡Que su ilusión se prolongue hasta que despierte la aurora! Sueña que las flores bailan en círculo a su alrededor, como inmensas guirnaldas enloquecidas, y le impregnan de suave perfume mientras canta un himno de amor, entre los brazos de un ser humano de mágica belleza. Pero sus brazos estrechan sólo un vapor crepuscular; y cuando despierte no lo estrecharán ya. No despiertes, hermafrodita, no despiertes todavía, te lo suplico. (Lautréamont, 1869, pp. 143-144).

En el arquetipo de El Mundo el ser que baila desnudo es andrógino, integra lo femenino y lo masculino, consciente de su identidad representa un equilibrio psíquico; permanece inmutable, sin cambiar su naturaleza, interactúa con ella conjuntando la polaridad de la energía positiva y negativa, enmarcado por una guirnalda que lo protege. Simbólicamente la carta significa una realización de sí, aceptando la condición de su cuerpo (Nichols, 1980). Es el deseo manifiesto en el sueño del hermafrodita, sin las transformaciones a las que recurre Maldoror para asimilarse en el mundo. ${ }^{3}$

\section{¡Oh pulpo de mirada de seda!}

En la primera edición de Los cantos se publicó tan sólo el primero, firmado anónimamente $\left.{ }^{* * *}\right)$ en 1868. La edición completa se imprimiría un año más tarde, bajo el seudónimo de Lautréamont y la sustitución del nombre de Dazet, compañero de

1 Recordemos que la homosexualidad era tratada en el psiquiátrico como alienación o trastorno mental hasta 1973, cuando se consideró como una orientación sexual.

2 El Diablo se relaciona con Maldoror, alter ego de Lautréamont, en la violencia y destrucción que ejerce a su paso; un mago de cualidades negativas, perversas. Las máscaras del diablo se despliegan en Maldoror en la metamorfosis: un héroe trágico, orgánico. En los mitos, las representaciones de las deidades fundacionales poseen también ambos sexos.

3 Otras cartas que se relacionan con el hermafrodita en Los cantos, son las de soledad e introspección. El Loco: intuición; El Ermitaño: sabiduría, conocimiento, iluminación individual, retiro voluntario (por deformación física); La Sacerdotisa: energía femenina y El Mago: prestidigitador o poeta. 
estudios de Ducasse en el Lycée de Tarbes. Las figuras adolescentes: Lohengrin, Elsenor, Reginaldo, Mario, Leman, y sobre todo Mervyn, representan sus dobles con un vínculo de amor homosexual. Dazet aparecerá en diversas animalizaciones como: pulpo de mirada de seda, rinoceronte, oso marino, sapo, ácarus sarcopte, etc. (Pichon-Rivière, 1946).

¡Oh pulpo de mirada de seda!, tú, cuya alma es inseparable a la mía, tú el más bello de los habitantes del globo terráqueo, que mandas sobre un serrallo de cuatrocientas ventosas $[\ldots]$ ¿...por qué no estás conmigo, con tu vientre de mercurio contra mi pecho de aluminio sentados ambos en algún roquedal de la orilla, para contemplar ese espectáculo que adoro? (Lautréamont, 1869, pp. 96-97).

El amor de Maldoror es otra vez hacia él mismo, en su desdoblamiento a Dazet, hacia su semejante, "el hombre se ha creído bello en todos los siglos, pero en realidad no cree en su belleza sino por amor propio" (Lautréamont, 1869, p. 97). El mar es entonces símbolo de la identidad, ensimismada. "Tu grandeza moral, imagen del infinito, es inmensa como la reflexión del filósofo, como el amor de una mujer, como la belleza divina del pájaro, como las meditaciones del poeta. Eres más hermoso que la noche" (Lautréamont, 1869, p. 102).

El hombre como un súper animal, "toda la animalidad está a su disposición”, es un asesino especializado. El conocimiento de éste es inventario de agresión respectiva del hombre y del animal. Entre los 185 animales que conforman el bestiario ducassiano, la garra y la ventosa son los símbolos de ataque dominantes en las transformaciones de Maldoror, siendo la ventosa la que otorga el goce sexual prolongado. Entre las encarnaciones de la ventosa se encuentran: la araña, la sanguijuela, la tarántula, el piojo, el vampiro y el pulpo. Las formas se hinchan y se multiplican en la metamorfosis, el tentáculo tiene la voluntad de poseer (Bachelard, 1939). Las diversas formas de ataque ocurren de manera gratuita o bien, por la felicidad que la metamorfosis le provoca, en ambos casos, la crueldad se relaciona con la conducta animal. El océano es concebido como espejo del lobo-hombre.

Bienaventurados son cuando no les envuelves, definitivamente, en tus hirvientes pliegues para ir a ver, sin ferrocarril, en tus acuáticas entrañas, cómo se encuentran los peces y, sobre todo, cómo se encuentran ellos mismos (Lautréamont, 1869, p. 101).

Lautréamont lleva al límite la ironía para hacer, a través de Los cantos, que el lector aspirara al bien. Esta fue su "excusa" por haber "cantado al mal" y fingir arrepentimiento en el plaquette inconcluso a un libro futuro, Poesías (1870). Sin embargo, llevaría a cabo en una tensión continua la dialéctica del amor-odio, "se mata lo que se ama". Instinto de vida y de muerte latentes ante una frustración por amar, como la obsesión de Maldoror por la belleza de Mervyn, a quien acecha hasta cometer su asesinato en el Canto VI.

En Sade la perversión y el libre albedrío ocurren al concebir al sujeto como objeto del placer, en donde la clase privilegiada goza de libertad sin límites, para 
alcanzarlo (Blanchot, 1949). Este es ejercido como ley humana, en Lautréamont es parte del instinto de supervivencia, el hombre es un objeto que cambia su forma en diversos animales, para ejercer la violencia ante sus semejantes y hacia el Creador. La profundidad del mar se presenta como el foso del alma humana, coincide con la carta del diablo al exhibir el aspecto sombrío del hombre, al enfrentar ese lado oscuro que nos habita. El diablo, con aspecto de murciélago, es también un chupador de sangre. Es la conciencia de la capacidad del hombre para cometer el mal (Nichols, 1980). El contacto con la naturaleza (animal), el origen primitivo de la agresión en el instinto del "hombre civilizado".

Dime, pues, si eres la morada del príncipe de las tinieblas. Dímelo... dímelo, océano (sólo a mí, para no entristecer a quienes no han conocido, aún, más que ilusiones), y si el soplo de Satán crea las tempestades que levantan hasta las nubles tus salobres aguas. Tienes que decírmelo, para que me alegre al saber que el infierno está tan cerca del hombre. (Lautréamont, 1869, p. 103).

\section{¡Me encontraba frente a mi primer amor!}

Buscaba un alma que se me pareciera, y no podía encontrarla. Registré todos los rincones de la tierra; mi perseverancia fue inútil. Sin embargo, no podía permanecer solo [...] era necesario que alguien tuviera las mismas ideas que yo (Lautréamont, 1869, p. 167).

Maldoror medita desde un acantilado en el mar, sobre quién podría "aprobar su carácter", amarlo. "La tempestad iba a iniciar sus embates y el cielo se oscurecía ya, haciéndose de un negro casi tan horrendo como el corazón del hombre" (Lautréamont, 1869, p. 168). Un navío comienza a hundirse, los pasajeros intentar alargar su vida contra la tormenta y las olas, "torbellino del abismo". Maldoror se propone disparar a todo aquel que se aproxime a la orilla para salvarse. "Entonces no tenía límites para mi furor; sufría accesos de crueldad y me convertía en terrible para quien se acercara a mis huraños ojos, siempre que perteneciera a mi raza" (Lautréamont, 1869, p. 172). El odio de Maldoror hacia el hombre lo lleva a matar por costumbre, hasta el hartazgo, con "insignificante goce". Observa cómo los pasajeros del navío hundido son devorados por seis tiburones. Un hembra tiburón hambrienta disputará los jirones de miembros flotantes. Maldoror dispara a uno de los tres tiburones que aún la circundan; se arroja al mar para salvarla; se encuentran.

Se miran a los ojos durante algunos minutos; y cada uno de ellos se asombra al encontrar tanta ferocidad en la mirada del otro [...] contuvieron su aliento con profunda veneración, ambos deseosos de contemplar por primera vez su retrato [...] se unieron por fin en un acoplamiento prolongado, horrendo y casto... ¡Por fin había encontrado a alguien que se me pareciera!... ¡Ya no estaría solo en la vida! (Lautréamont, 1869, pp. 174-175).

Maldoror solo es capaz de amar en el mar. El encuentro sexual con la hembra tiburón es un "fuego negro y frío". Ante el amor la conciencia del mal pervive. "La 
función primera de la imaginación es crear formas animales" (Bachelard, 1939). Maldoror ama a una hembra tiburón y no a una semejante de su especie. Quizá es la única estrofa en la que se concluye un encuentro sexual, la mayoría de los acercamientos de Maldoror con alguna mujer son a partir de la prostitución, la locura o para asesinar a una niña -con excepción de la energía femenina creadora y destructora de la naturaleza, y la delicadeza del hermafrodita-. La consumación con la hembra tiburón borra los límites entre el animal y el hombre, equilibra con ella nuevamente la energía del yin y del yang, encontrándola su semejante en crueldad, desde el narcisismo.

\section{Conclusiones}

\section{(...y nadie sabe la cantidad de amor que contienen mis aspiraciones a lo bello)}

El ideal de belleza y la estética en Los cantos van acompañados por un guiño de crueldad. Ducasse en su plaquette incluso Poesías se "arrepiente" de haber "cantado al mal", alegando haber exagerado el tono para "oprimir al lector a desear el bien", llevando la ironía al límite. Las transformaciones en Maldoror tienen origen en el cuerpo y en la sexualidad como una pulsión latente, ya desde la frustración por ejercerla o como instinto, que desemboca en la violencia verbal. Las metáforas están ligadas a la metamorfosis, y esta funciona como una adaptación al "medio imaginario", a la atmósfera en la que se desarrolla cada estrofa (Bachelard, 1939).

Los arquetipos jungianos funcionan como representaciones de la naturaleza humana (psíquica) manifestados en pulsiones por el inconsciente. Cada arquetipo corresponde al ciclo o camino del héroe trágico (Maldoror: orgánico) ante las vicisitudes de la vida. Manifestaciones que dan origen en la imaginación a las formas animales.

La danza del andrógino en la carta de El Mundo o en el hermafrodita en Los cantos simboliza el acto de creación, en este caso, de la poesía, y no un acto de insania. Los dobles adolescentes de Maldoror, a lo largo de la obra exhiben un juego de espejos en donde la preferencia por lo semejante se evidencia en diversos grados, asimilando el narcisismo como indicio de homosexualidad.

Dazet, colega de estudios del joven Ducasse, será reemplazado por múltiples nombres y animales en la edición completa de Los cantos; una transposición autobiográfica que intentará borrar para no dejar memorias o rastros de su existencia, hasta que una fotografía suya es encontrada por el biógrafo Jean-Jaques Lefrère en un álbum familiar de Dazet.

En el mar sucede la realización del encuentro sexual entre Maldoror y la hembra tiburón. El mar y Maldoror como reflejo del hombre y de sí, se vinculan con la carta 
de El Diablo, en donde fundida la corporeidad entre bestia y hombre: el mar / Maldoror, posibilita la unión con una hembra tiburón, con las implicaciones éticas que conlleva la metamorfosis. Sin perder de vista que no es la sexualidad de Ducasse lo que está en juego, sino cómo es ejercida en la obra.

\section{Bibliografía}

Bachelard, G. (1997). Lautréamont. (Trad. de Angelina Martín del Campo). México: FCE. (1939).

BBC Mundo. (2017). Muere Robert Spitzer, el psiquiatra que desmintió que la homosexualidad fuera una enfermedad - BBC Mundo. [online] En: http://www.bbc.com/ mundo/noticias/2015/12/151228_ciencia_muere_robert_spitzer_psiquiatra_homosexualidad_ch [Consultado 7 Jun. 2017].

Blanchot, M. (1990). Lautréamonty Sade. (Trad. Enrique Lombera Pallanes). México: Fondo de Cultura Económica. (1963).

Ducasse, I. (2001). Poesías. (Trad. de Braulio Arenas). México: Coyoacán. (1870).

Lautréamont, C. (2004). Los cantos de Maldoror. (Trad. de Manuel Serrat Crespo). España: Cátedra. (1869).

Lefrère, J. (2008). Lautréamont. París, Francia: Flammarion.

Nichols, S. (1989). Jung y el tarot. (Trad. Pilar Basté). Barcelona, España: Kairós. (1980).

Pichon-Rivière, M. (1992). Psicoanálisis del conde de Lautréamont. Argentina: Argonauta. (1946). 